Revista de Ensino em Artes, Moda e Design

Dossiê 6

A modelagem integrada ao projeto de Moda no âmbito do ensio

\title{
RELAÇÕES INTERTEXTUAIS ENTRE MODA E ESCULTURA
}

\section{Relations intertextuelles entre mode et sculpture}

\section{Intertextual reelationship between fashion and sculpture}

Sandra Regina Ramalho e Oliveira ${ }^{1}$

\footnotetext{
${ }^{1}$ Sandra Ramalho é docente da UDESC, atuando em 2020 como Investigadora Visitante na UdG, Universitat de Girona, España. Doutora em Comunicação e Semiótica pela PUC/SP, fez pós-doutorado na França. É autora dos livros "Imagem também se lê", "Moda também é texto", "Sentidos à mesa" e "Diante de uma imagem". Presidente da ANPAP, gestão 20072008, coordenou o PPGAV/UDESC entre 2009 e 2011.

E-mail: ramalho@floripa.com.br | Lattes: http://lattes.cnpq.br/0870589343786662
} 


\title{
Resumo
}

Os estudos intertextuais, que têm como objeto fenômenos relacionais entre manifestações diversas, encontram bases teóricas na linguagem verbal. Assim, investigações sobre a visualidade buscam teorias da linguística para aproximações, as quais demandam análises, adequações. Desde os conceitos bakhtinianos "dialogia" e "polifonia", passando por "intertextualidade", de Kristeva, bem como "tradução" (verbal), abordado por inúmeros autores, Calabrese é exceção, pois ocupou-se de tradução no campo da visualidade. Ramalho e Oliveira e Jardim Filho também se excluem, apresentando propostas intertextuais no campo visual. Aqui analisa-se uma articulação entre escultura e moda, amalgamando em imagens de dorsos, nus ou vestidos, o conceito curatorial de uma mostra ocorrida em 2019, em Paris.

Palavras-chave: Intertextualidade; Escultura e Moda; Dorso; Emile-Antoine Bourdelle; Palais Galliera.

\begin{abstract}
Intertextual studies, whose object is relational phenomena between different manifestations, find theoretical bases in verbal language. Thus, investigations on visuality seek linguistic theories for approximations, which demand analyzes, adjustments. From the Bakhtinian concepts "dialogy" and "polyphony", through Kristeva's "intertextuality", as well as "translation" (verbal), approached by numerous authors, Calabrese is an exception, as he dealt with translation in the field of visuality. Ramalho e Oliveira and Jardim Filho also exclude each other, presenting intertextual proposals in the visual field. Here, an articulation between sculpture and fashion is analyzed, amalgamating in images of backs, naked or dressed, the curatorial concept of a show that took place in 2019, in Paris.
\end{abstract}

Keywords: Intertextuality; Sculpture and Fashion; Back Side; Emile-Antoine Bourdelle; Palais Galliera.

\section{Résumé}

Les études intertextuelles, dont l'objet est les phénomènes relationnels entre différentes manifestations, trouvent des bases théoriques dans le langage verbal. Ainsi, les investigations sur la visualité recherchent des théories linguistiques pour les approximations, qui demandent des analyses, des ajustements. Des concepts bakhtiniens « dialogie » et « polyphonie », en passant par « l'intertextualité » de Kristeva, ainsi que la « traduction » (verbale), abordée par de nombreux auteurs, Calabrese est une exception, puisqu'il a traité de la traduction dans le domaine de la visualisation. 
Ramalho e Oliveira et Jardim Filho s'excluent également, présentant des propositions intertextuelles dans le domaine visuel. Ici, une articulation entre sculpture et mode est analysée, fusionnant en images de dos, nus ou habillés, le concept curatorial d'une exposition qui a eu lieu en 2019, à Paris.

Monts-clés: Intertextualité; Sculpture et mode; Dos; Emile-Antoine Bourdelle; Palais Galliera.

\section{ESTUDOS INTERTEXTUAIS}

Necessário se faz apresentar uma premissa, antes de se falar em intertextualidade: a semiótica discursiva adota o termo "texto" para designar unidades de análise pertinentes a outras linguagens além da verbal, pois como já postulavam Greimas e Courtés na primeira versão do seu "Dicionário de Semiótica" (1989), os termos discurso e texto podem ser usados "para designar o eixo sintagmático das semióticas não-linguísticas: um ritual, um balé podem ser considerados como textos" (p. 460). Assim, relações entre textos visuais podem ser consideradas e denominadas intertextualidades.

Investigações sobre textos visuais e sincréticos por meio de analogias ainda são insuficientes. Entretanto, experiências não sistematizadas dão conta de que ao se observar duas unidades de análise em relação, com mais profundidade se pode analisá-las, uma vez que o que há e o que não há numa e noutra são dados visuais cruzados que se defrontam e se complementam, simultaneamente.

Se para a análise de textos visuais a proposta é instigante, melhor ainda se presta para processos educacionais sobre a visualidade. Todavia, o que pode ser adotado como uma espécie de abordagem metodológica, permanece ainda pouco explorada entre nós, não obstante a existência de teorias que a amparem. Estas investigações e proposições teóricas encontram-se prioritariamente no âmbito da linguagem verbal, dando conta de sustentar diferentes fenômenos que se caracterizam como intertextualidade, o que não acontece no campo das linguagens visuais e sincréticas, mas podem servir de base para pesquisas empíricas, já que o objeto teórico é um só: o sentido. Ou seja, o objeto de estudo é a apreensão dos efeitos de sentido, fenômeno inerente a qualquer linguagem, verbal, visual, sonora, cênica ou miscigenada, as quais permitem análises ou leituras. $O$ intuito de qualquer linguagem ou modo de expressão, é "dizer" algo.

Mikhail Bakhtin (1988, p. 88) postula que toda manifestação consiste em uma relação com um texto anterior, seja uma resposta, uma negação, uma reação, apenas gestual, ou uma nova versão, como no caso da paráfrase, que é o que está sendo feito neste parágrafo, em relação ao pensamento de Bakhtin. O linguista russo denomina esta inexorabilidade de dialogia.

Este autor diz que "apenas o Adão mítico que chegou com a primeira palavra num mundo virgem, ainda não desacreditado, somente este Adão podia realmente evitar por completo esta múltipla orientação dialógica do discurso alheio para o objeto" (apud FIORIN, 2008, p. 18). E o trecho anterior neste texto verbal é outra forma 
de inter-relação intertextual, denominada citação; nela não é mantida apenas a ideia, como no caso da paráfrase, em que outras palavras são usadas para expressá-la; na citação, as próprias palavras, além da ideia, são mantidas conforme a autoria anterior.

Deste modo, dialogismo consiste em um princípio unificador na obra de Bakhtin, expressando-se de diversas maneiras, como a paráfrase, a citação e a versão, fenômenos de linguagem passíveis de estudo. Dialogia é um conceito que dá conta das relações que se estabelecem entre enunciados ou discursos, tratando do modo como se articulam os sentidos por meio das linguagens. Bakhtin concebe, na verdade, um desdobramento do conceito em dois e aprofunda questões relacionadas a diversos gêneros de discurso. Embora consista em terreno fértil para se plantar questões acerca das linguagens contemporâneas, visuais e sincréticas, a herança bakhtiniana restringe-se exclusivamente à linguagem verbal.

Sobre as duas dimensões do conceito de dialogia por Bakhtin, Niedzieluk (2017, p. 11) afirma que

o dialogismo pode ser desdobrado em dois aspectos: o da interação verbal entre o enunciador e o enunciatário no espaço do texto, e o da intertextualidade/interdiscursividade no interior do discurso (diálogo entre os muitos textos da cultura que se instala no interior de cada texto e o define). Esta forma de dialogismo também é conhecida como polifonia, isto é, as diferentes vozes instauradas em um texto/discurso.

Por outro lado, anos após as teorizações de Bakhtin, na década de 1960, a franco-búlgara Julia Kristeva retoma o conceito de dialogia e redimensiona-o. Entre os pressupostos que ela adota está a priorização do estudo do texto orientando para as questões do sentido e da interpretação. Trata-se de interpretar um texto não como um reservatório de um sentido fixo, mas como o lugar de uma interação complexa entre diferentes textos. Desta relação nasce um sentido, ele mesmo instável, variável, em função da interação que privilegia o intérprete. Outro aspecto que expande a noção de dialogia nas proposições de Kristeva é o fato de ela considerar a existência de intertextualidade não apenas entre os textos já criados com os atuais, mas ainda destes com os que ainda não foram escritos.

Alguns teóricos se dedicaram a fazer classificação dos fenômenos intertextuais, como Genette; Piègay-Gros; Koch; Ramalho e Oliveira e Jardim Filho. Gérard Genette (1979) criou o termo transtextualidade para designar o conjunto de possibilidades, decorrente do modo de operar de cada texto, a partir dos seus arranjos linguísticos. Assim, segundo ele, a transtextualidade pode se apresentar dos seguintes modos: intertextualidade (relação evidente entre um texto em outro, como na citação explícita, na alusão ou no plágio); paratextualidade (relação entre o texto e os que estão no seu entorno, como títulos, prefácios e epígrafes); metatextualidade (relação de comentário, crítica, resenha, como o texto referenciado); hipertextualidade (relação entre certo texto e outro dele originado, como o pastiche e a paródia; e a arquitextualidade (relação de um texto com o respectivo gênero discursivo).

Outra estudiosa que se dedicou à classificação de fenômenos de linguagem que se relacionam entre si está Piègay-Gros (1996). Ela divide as relações intertextuais apenas em duas categorias: relações de copresença e as de derivação. 
Outra proposta taxionômica é a de Koch (2004), que equivale intertextualidade à polifonia e postula sua divisão entre intertextualidade em sentido amplo e intertextualidade stricto sensu. Em sentido amplo, são as relações constitutivas de qualquer discurso; e a intertextualidade stricto sensu ocorre quando um texto é inserido no outro, evidentemente, por conta da memória coletiva ou individual dos interlocutores.

Ramalho e Oliveira e Jardim Filho (2017, p. 621), após análise de diversas possibilidades de intertextualidade, afirmam que uma

\begin{abstract}
questão a destacar é a mutabilidade, a flexibilidade das classificações, ou seja, não se trata de apenas colocar uma etiqueta definindo de que caso se trata este ou aquele texto; percebeu-se que um mesmo texto pode ser considerado um ou outro fenômeno, dependendo da bagagem do leitor, de suas experiências de vida, ou seja, do contexto, em última instância. De modo idêntico, percebeu-se que um mesmo texto visual pode consistir, em determinada circunstância, em uma paródia, ou uma cópia, uma citação ou até um plágio.
\end{abstract}

Estes autores de dedicam a enfocar fenômenos intertextuais na visualidade, embora fundamentados, em grande parte, nos pressupostos da linguagem verbal, como na tese de doutorado de Airton Jordani Jardim Filho (2019), intitulada "Intertextualidade como proposta para o ensino da arte: um exercício a partir das concepções visuais de Aloísio Magalhães".

Importante se faz ainda destacar, no contexto desta revisão teórica, que outro dos poucos autores que se ocupou dos fenômenos de intertextualidades na linguagem visual e nas linguagens sincréticas é Omar Calabrese (2008), pois os demais estudiosos se dedicam às intertextualidades no campo verbal. O conceito intertextual com o qual ele trabalha é tradução. E propõe a tradução de dois modos: molar e molecular. A molar é fiel às ideias, ou ao plano de conteúdo, concedida liberdade para traduzir tais ideias; e a tradução molecular é aquela mais "ao pé da letra", isto é, aquela onde não apenas o Plano de Conteúdo, mas também o Plano de Expressão são identificáveis em relação ao "testo de partenza" (texto de partida), expressão usada por Calebrese, evitando referir-se a um texto "original".

\title{
2 MODA E ESCULTURA
}

De julho a novembro de 2019, o Museu Bourdelle, local onde funcionou o ateliê do escultor Emile-Antoine Bourdelle (1876-1929), em Paris, abrigou a mostra "Back Side/Dos à la mode", que se propunha a mostrar relações entre moda e escultura, tendo como referência o dorso. Ou seja, como vêm sendo apresentados os dorsos, notadamente os femininos, por costureiros ${ }^{1}$ obviamente conhecedores de corpos, usando tecidos para envelopá-los? E como as costas, em geral, foram moldadas por um escultor, um evidente estudioso do corpo humano?

A mostra apresentava trajes do século XVIII até a atualidade e realizou-se no Museu Bourdelle, mas foi promovida pelo Palais Galliera, o mais importante museu

${ }^{1}$ No Brasil, "costureiro (a)" é pejorativo; aqui esses profissionais se autointitulam estilistas ou designers de moda; mas na França, esta é uma classe honrada e de sucesso, les couturiers. 
de moda de Paris, que estava em reformas.

O curador foi Alexandre Samson, que até então tinha sido assistente do diretor do Galliera, Olivier Saillard, inclusive na curadoria de uma exposição dedicada aos trabalhos da estilista Madame Grès, em 2011, a qual, de certo modo, com seus drapeados, foi uma antecipação de "Back Side/Dos à la mode". Daí em diante, Samson desenvolveu pesquisas sobre o dorso feminino, em arquivos e em bibliotecas, mas também junto a profissionais da área médica, incluindo psiquiatras, osteopatas e fisioterapeutas, entre outros. De acordo com a crítica, tal trabalho valeu a pena, pois o resultado foi rico e apaixonante.

Figura 1: Dorsos, exposição "Back Side/Dos à la mode" (2019)
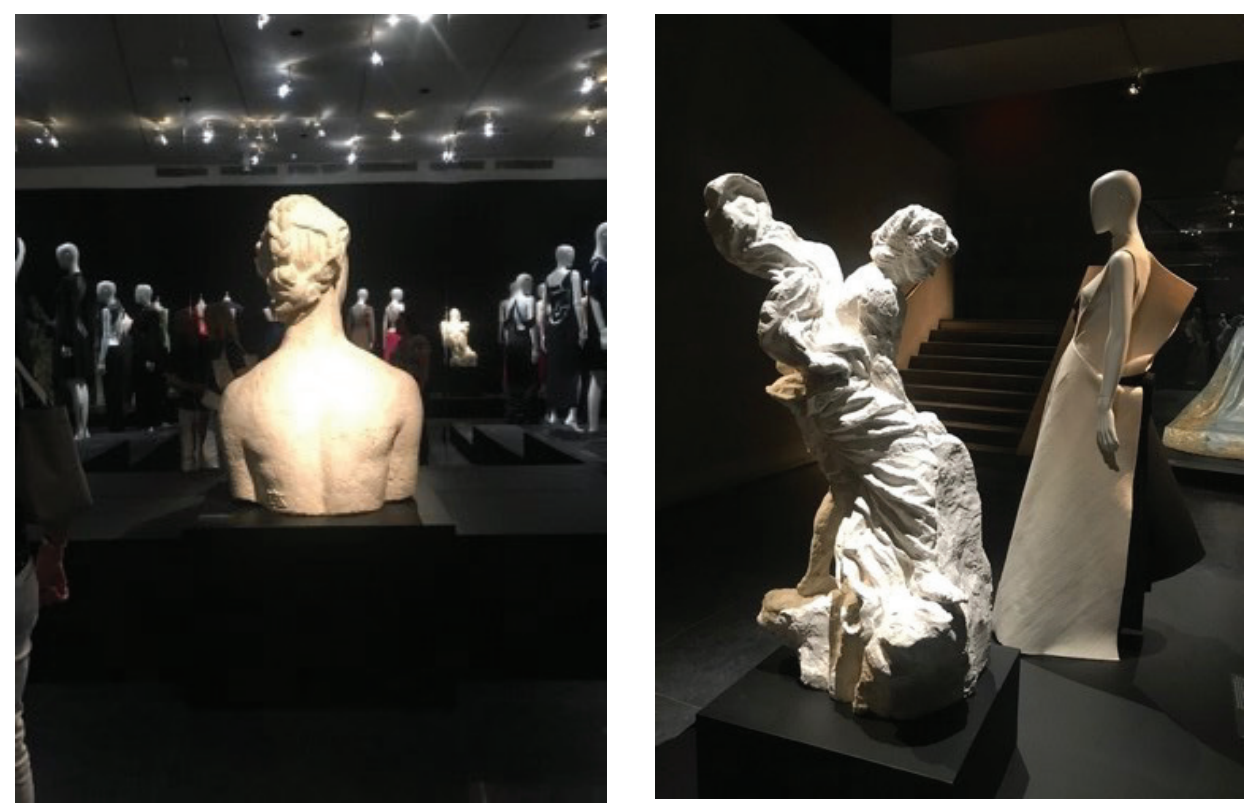

Fonte: Autora.

Ambas as imagens anteriores registram tomadas iniciais do percurso expositivo: na figura $1^{2}$, uma imagem de Bourdelle, de costas para o público, como que aprecia vários manequins de costas também. Em toda a mostra havia o contraste entre os fundos negros que mais destaque dava às esculturas e aos modelos, sempre claros, ressaltados por uma iluminação irrepreensível. Na figura 1 o mesmo fenômeno estético do contraste se dá, mas em outro modo de oposição, o contraste entre linhas e formas sinuosas de um Bourdelle, numa construção barroca, em confronto com um modelo minimalista, clássico, composto por linhas e formas retilíneas.

Segundo Samson ${ }^{3}$, não era exatamente uma exposição sobre costureiros, mas sobre o corpo humano. Daí suas consultas aos profissionais da saúde, que lhe deram subsídios não só anatômicos, mas de saúde preventiva. Por exemplo, um ortopedista Ihe falou que já atendeu muitas mulheres com problemas na coluna por terem tentado fechar o zíper nas costas, sozinhas. E ele complementa chamando a atenção para o fato de que esta situação, a de necessitar ajuda para fechar vestidos nas cos-

\footnotetext{
${ }^{2}$ As imagens deste artigo foram capturadas pela autora do texto verbal, exceto o torso de Bourdelle da figura 5, extraída do endereço https://www.gettyimages.co.uk/detail/news-photo/emilleantoine-bourdelle-sculptures-amp-drawings-exhibition-news-photo/1078687948, em 7 de novembro de 2019 .

3 Entrevista concedida a Valentin Pérez, Le Monde, Paris, 6 de julho de 2019.
} 
tas, é bastante democrática, pois acontece em todas as classes sociais. Isto é uma alusão à diferença do tempo atual daqueles em que se vestir era uma cerimônia para os membros da realeza e os súditos que os ajudavam a se vestir, ou que na verdade os vestiam, em certos casos assistidos por nobres privilegiados, convidados para tal cerimônia.

Portanto, não apenas sob o ponto de vista biológico a exposição se pautou, pois o corpo é abordado também em suas dimensões sociais e psicológicas, interrogando qual a nossa relação com o nosso próprio dorso e com os das outras pessoas. Por outro lado, pensar sobre as costas lembra ao ser humano seus próprios limites, pois ele, o ser humano, fica escondido da visão pelo seu próprio corpo em posição frontal, o ângulo visto habitualmente quando se está de frente para o espelho para uma autoavaliação, assim como é ocultado sob o ponto de vista que apresentamos aos nossos interlocutores, e eles a nós.

Sob algumas dimensões, esta parte do corpo está associada, em diversos idiomas, a sentidos disfóricos, negativos. Senão, o que significa "dar as costas" para alguém? E ter "costas largas"? E "costas quentes"? Querer "ver alguém pelas costas" é querer se livrar dessa pessoa. Em inglês, back é usada em diversas expressões, entre elas, "back out", que é mudar de ideia ou não cumprir o prometido; já "behind [...] back" é fazer algo às escondidas de alguém; "go back" é ir embora. Em francês, dos é igualmente base para várias expressões, como em outros idiomas, metafóricas e em parte, pejorativas: "avoir bon dos" é servir de pretexto, ser acusado; "avoir [...] sur son dos" é carregar o "peso" de algo ou alguém; e "se mettre quelqu'un à dos" é fazer de alguém seu inimigo.

Estamos tratando da parte mais plana do corpo feminino e tudo que se coloca - ou não - sobre essa superfície tem total visibilidade para os olhares que a ela se dirigem, pelas costas, sem divisar a identidade facial do seu portador, que não deixa de ser, no mínimo, um coautor do texto, seja ele verbal ou visual. Não é à toa que este espaço tem sido tão usado na moda casual contemporânea, para externar posicionamentos políticos ou sociais ou apenas para marketing. Mesmo as marcas, antes escondidas em delicadas e discretas etiquetas internas, hoje ganham visibilidade nesse suporte móvel e fugidio, o plano das costas, nas pessoas de costas. 


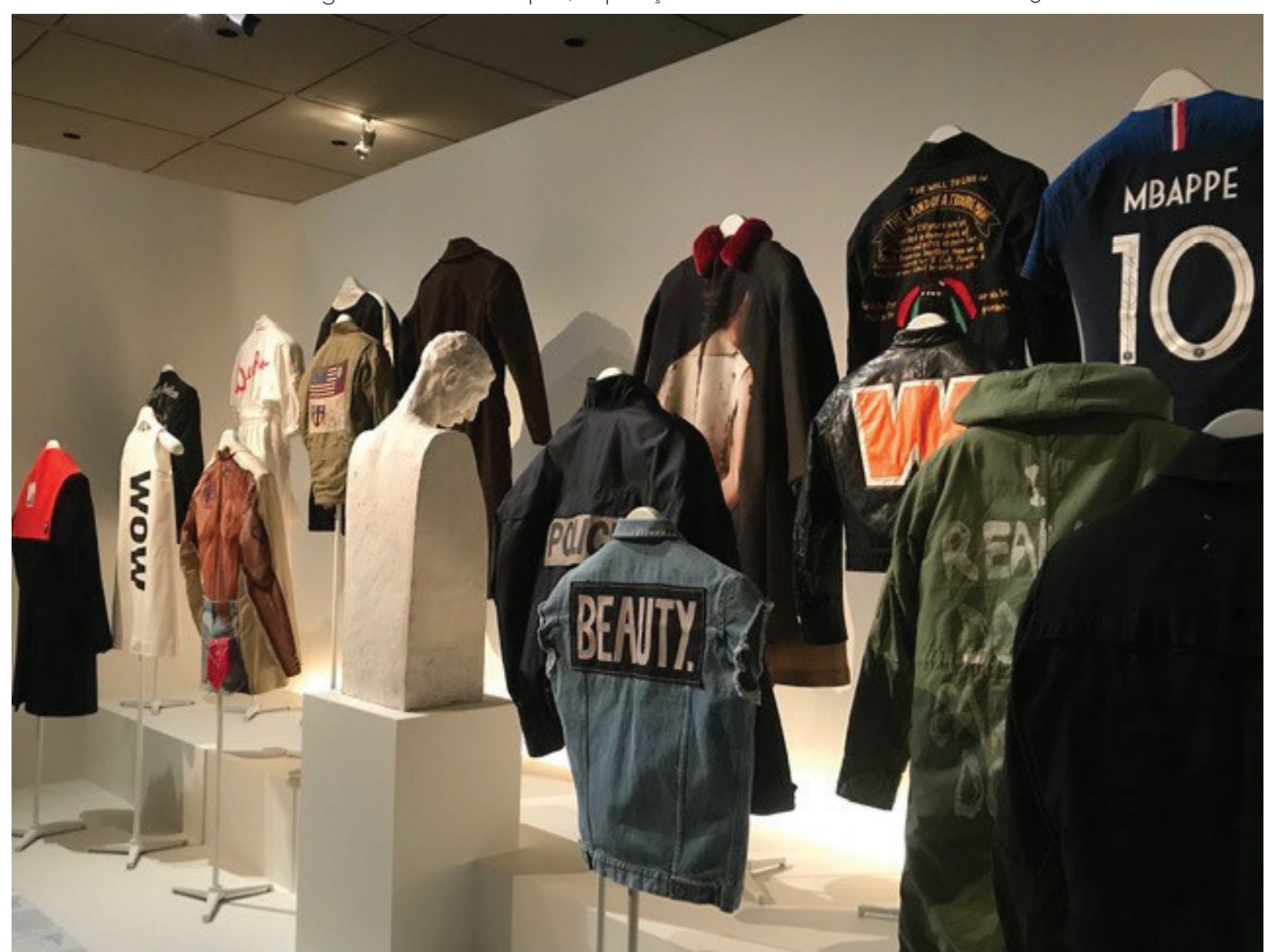

Fonte: Autora.

Na figura 2 observa-se que nem só a alta costura foi objeto da atenção do curador, mas se vê que as mais diversas dimensões das costas foram exploradas. E diante das estruturas de sustentação das costas de vários trajes, um dorso artificialmente plano dá a deixa para a leitura de mais um conjunto da mostra.

Os espaços receberam títulos, em torno dos quais obras e trajes foram organizados: "As asas"; "O obstáculo"; "A carga"; "O dorso nu". Em "As asas" (figura 3) foram apresentados trajes de uma mostra conceitual de Thierry Mugler (1984), que dialogavam com um cupido de autoria de Bourdelle. Eram trajes de um desfile-espetáculo de outono-inverno de 1984-1985, intitulado "O inverno dos anjos". A etiqueta esclarecia que os materiais eram tafetás e sedas, além de plumas pintadas de dourado, prateado ou de azul, entretecidas pela Maison Lemarié, criada em 1880, contando com profissionais em extinção, especializados em aplicação de plumas naturais (plumasiers) e flores de tecidos finos (fleuristes) para uso da alta costura. Não foi mencionado na mostra, mas "Angel" é o nome de uma das fragrâncias mais conhecidas entre as que têm a assinatura de Mugler, o que se insere no campo semântico da figura 3. Seu frasco é azul, em forma de estrela. 
Figura 3: As asas, exposição "Back Side/Dos à la mode" (2019)

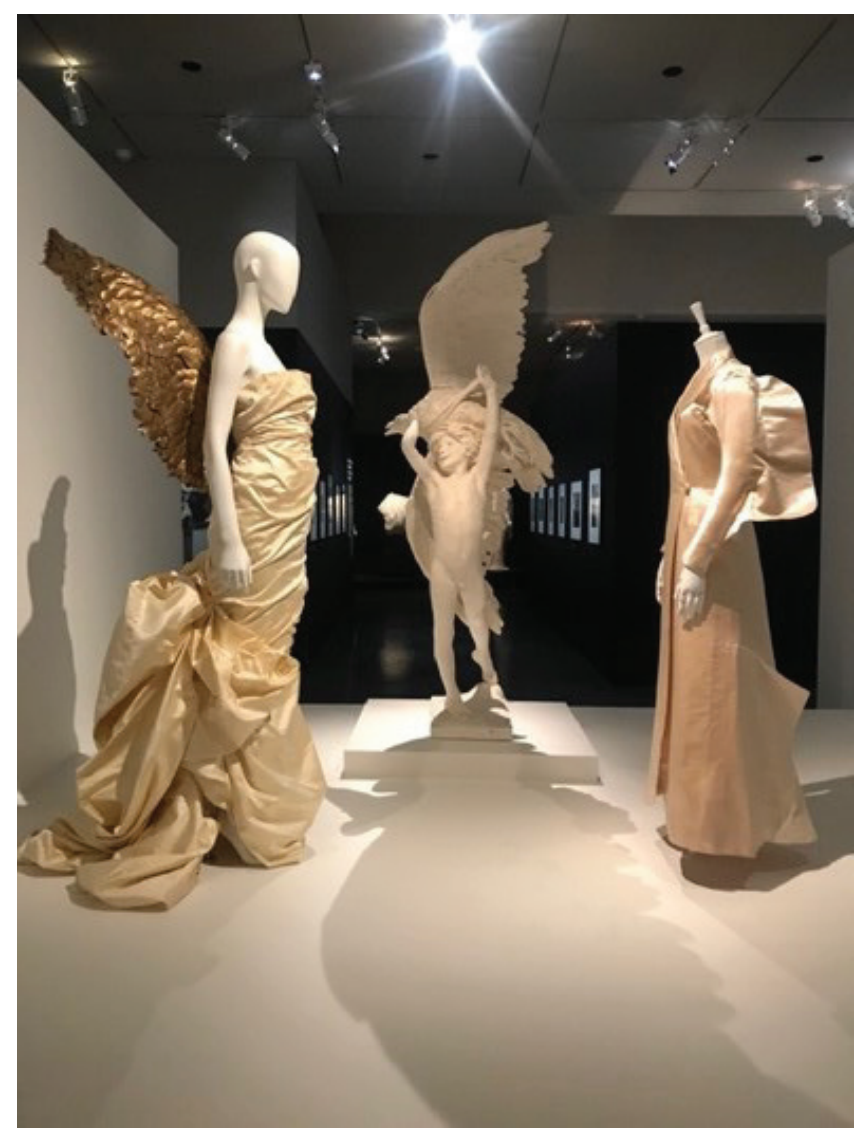

Fonte: Autora

Tanto no uso das costas como portadoras de mensagens filosóficas ou comerciais há uma espécie de dissociação da identidade, por serem vistas com as pessoas de costas, como também no caso das esculturas de dorsos sem rosto, pois repete-se essa dissociação identitária. Por acaso ou não, os manequins que se vê nas vitrinas muitas vezes não têm cabeça, ou o rosto é apenas um esboço de traços faciais; e há os suportes de roupas que sequer simulam ser um corpo, são apenas armações de metal ou madeira.

$\mathrm{Na}$ escultura, sob este aspecto, muitos dos dorsos de Bordelle ou de outros artistas através do tempo se assemelham: apresentam-se sem rosto, sem cabeça. Talvez uns por serem considerados por seus autores, inacabados, apenas estudos; outros são, como é sabido, resultado de intempéries ou outro tipo de acidente, que se houve por bem não restaurar, como no caso da Vênus de Milo. Mas há aqueles cujo objeto mesmo é o dorso, em si.

Importante aqui se faz esclarecer uma questão linguística: em português, têm-se os vocábulos dorso e torso. São palavras semelhantes na escrita, na pronúncia e no significado, mas não são sinônimos. Enquanto torso é sinônimo de tronco, portanto, tridimensional (figura 4), dorso é sinônimo de costas, portanto, pode ser bidimensional (figura 5), o que não é exatamente o caso da figura 5. 
Figuras 4 e 5: Torso de Bourdelle e dorso da exposição "Back Side/Dos à la mode" (2019)
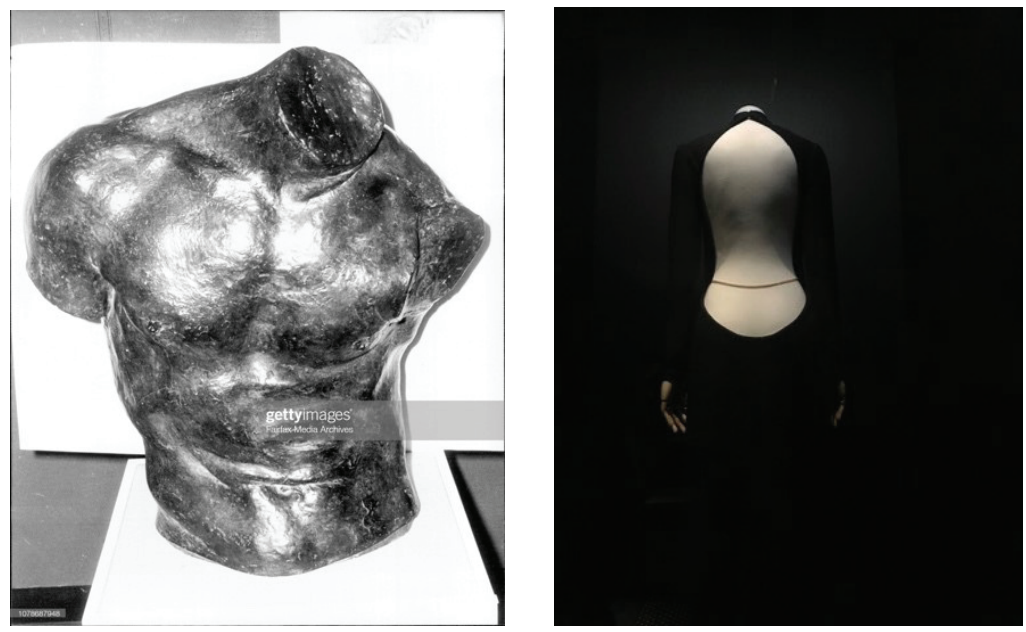

Fonte: Getty Imagens e autora. ${ }^{4}$

Os trajes da exposição "Back Side/Dos à la mode" eram como que fragmentos de esculturas jamais mostradas, que possibilitam revisitar os corpos em outras perspectivas; e embora algumas esculturas de Bourdelle já fossem conhecidas, sua reapresentação nesse contexto possibilitava que elas fossem ressignificadas. No diálogo entre a rudeza ou a da rigidez da pedra, do metal ou mesmo do gesso dos moldes e a leveza e a fragilidade dos tecidos, reforçado pelo ambiente fabril do imenso ateliê, surgia um estranhamento no público que, a partir dessas manifestações díspares assim "costuradas", passava e refletir sobre os desafios da ousada proposta curatorial e sobre a narratividade por ela proposta. Além dos trajes, em si, a moda era apresentada em outros modos de vulnerabilidade e impermanência, como em filmes e fotografias, como as mostradas na figura 6 , ampliando o suporte para além dos manequins de vitrinas.

Figura 6: As costas. ${ }^{5}$
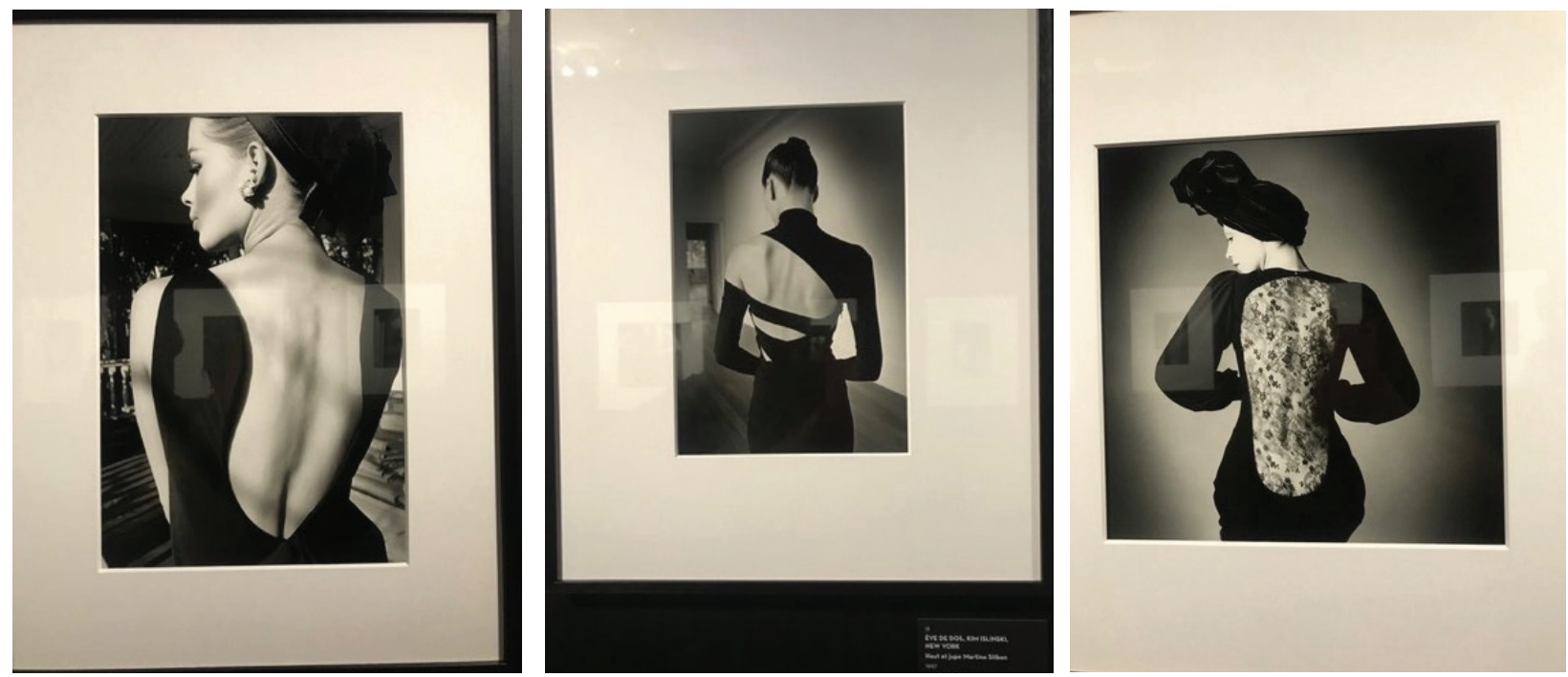

Fonte: Autora.

\footnotetext{
4 Figura 5 extraida do endereço https://www.gettyimages.co.uk/detail/news-photo/emille-antoinebourdelle-sculptures-amp-drawings-exhibition-news-photo/1078687948, em 7 de novembro de 2019. 5 Vestido de Bill Blass, foto de Maurice Rentner, publicada na revista Haper's Bazaar (1964); Eva de costas, foto de Kim Islinski, traje de Martine Sitbon; O dorso em renda, foto de Marina Schiano, Vestido Yves Saint Laurent (1970), publicada na Vogue de Paris.
} 
O vidro que protegia estas fotos, juntamente com os focos de luz, dado o reflexo que causavam, dificultaram o enquadramento das metafotos desta autora. Ainda assim, pode-se observar na figura 6, primeira imagem, "As costas de Astrid Heeren", Vestido de Bill Blass, foto de Maurice Rentner, publicada na revista Haper's Bazaar, 1964; na figura 6, segunda imagem, "Eva de costas", foto de Kim Islinski, traje de Martine Sitbon; e na figura 6, terceira imagem, "O dorso em renda", foto de Marina Schiano, Vestido Yves Saint Laurent, 1970, publicada na Vogue de Paris.

Em conjunto de fotografias ou em conjunto de trajes dialogando com esculturas, as imagens foram dispostas ao longo de salas e corredores de dois andares da edificação de tijolos à vista, situada no XVième arrondissement parisiense, que tem jardins internos, pés direitos imensos e luz natural em alguns espaços, como bem convém ao ateliê de um artista, ou de um escultor. Nos salões inundados de sol ficavam as roupas emprestadas por colecionadores, pois os clássicos da coleção do Galliera não podem ser expostos à luz natural. Nos demais espaços, tudo era negro, exceto o que se encontrava sob os focos da iluminação.

Outros focos que a curadoria convidava o público a refletir é a questão das caudas nos vestidos. Inicialmente mais usado em vestidos de noivas, para diferenciá-las das demais convidadas que usavam trajes da mesma cor, a cauda passa a ser uma marca de distinção; isto se evidencia como se não fosse apenas pela prodigalidade no uso de tecido, mas pelo fato de que simplesmente não se pode aproximar da pessoa pelas costas. A mostra não apresentou vestidos de noiva, mas um conjunto de trajes com cauda, que no seu elemento intertextual, apresenta a marca de distinção antes privativa das noivas.

Figura 7: Vestidos com cauda.

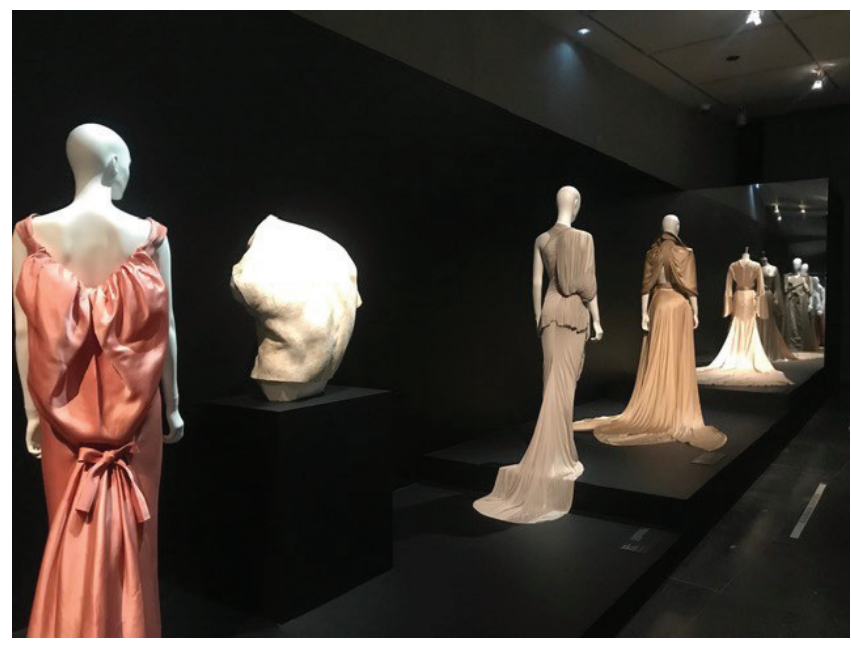

Fonte: Autora.

Mas é claro que a sensualidade não poderia deixar de ser objeto de reflexão, pois cobertas ou descobertas, as costas sempre encerram uma promessa ou uma oferta. Como em muitos dos dados aqui apresentados, catálogo, textos de parede e mesmo as etiquetas foram a fonte. $E$ foi numa etiqueta que se encontrava uma frase do costureiro inglês Alexander McQueen (1969-2010): “o dorso é uma zona erógena pouco explorada. [...] Para mim, esta parte do corpo, não exatamente as nádegas, mas a curva da cintura é a zona mais erótica de qualquer corpo, homem ou mulher" (figura 8). 
Figura 8: O dorso.
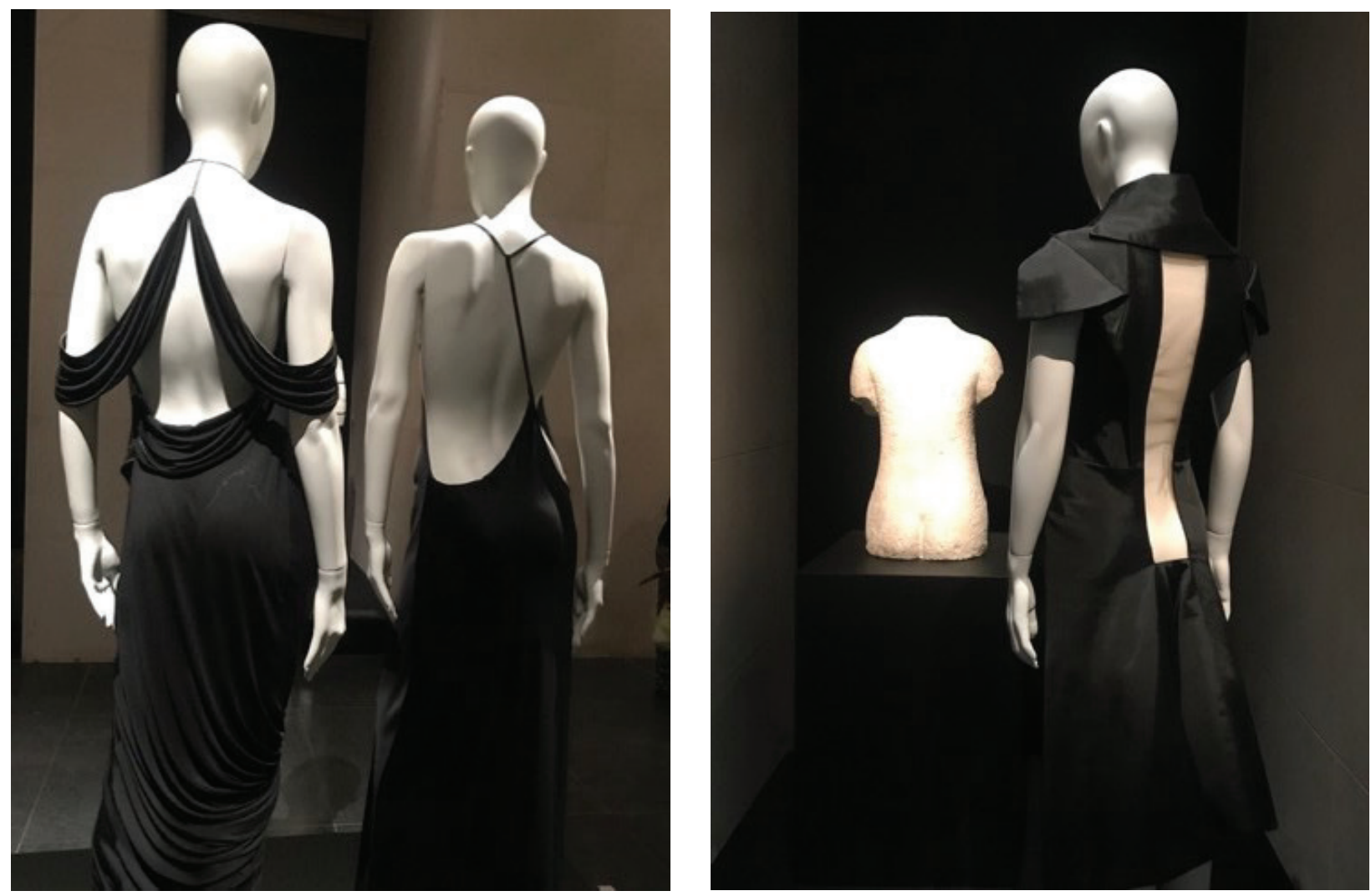

Fonte: Autora.

Em outras palavras, o conceito curatorial, ao ter como eixo o dorso, por si só já traz a sensualidade como fator inerente a ele. Isto porque a nudez está presente muito frequente nas esculturas; mas o erotismo está mais ainda na ambiguidade do jogo de esconde-esconde que pressupõe o fato de que a portadora do traje desconhece, inocentemente, aquilo que coloca à disposição do olhar de quem seu corpo atrai; por não vê-lo, é como se fosse fruto de um descuido fortuito, e não uma provocação, como um decote frontal.

\section{CONSIDERAÇÕES}

A escolha das obras de Emile-Antoine Bourdelle para dialogar com os trajes que deixam as costas femininas desnudas, a maioria entre as roupas expostas, não foi gratuita. É que Bourdelle tinha um encantamento pelas formas que os dorsos e os torsos podem assumir, consistindo em um desafio esculpi-los. Ele reproduziu o torso de seu professor Auguste Rodin e também o do escritor Anatole France. Bourdelle ainda tirou o molde de seu próprio torso - e dorso - em gesso, e quando da sua morte, sua filha mandou fundi-lo em bronze.

O que fez o curador Alexandre Samson foi construir uma teia intertextual: ao perceber o potencial da obra de Bourdelle no que se refere ao dorso, teceu relações com produtos icônicos da moda que, na verdade, omitem as costas, ou seja, a formatação das costas não tem tecido e, no modo da ausência de matéria, ou do continente, destaca o conteúdo, ou os dorsos de quem os vestiu, os dorsos humanos, 
na grande maioria, femininos. Neste caso, a intertextualidade se deu na ausência de material de moda que, no retorno, volta aos dorsos que foram os modelos de Bourdelle. Ou de outro modo, aludindo a Magritte (ceci n'est pas.../isto não é...), o dorso humano não estava nem na obra de Bourdelle, nem nos produtos da moda. Em síntese, ambas as linguagens, escultura e moda, têm seus modos próprios para traduzir, intertextualmente, em uma tradução molar (CALABRESE, 2008), o texto visual, uma parte nem sempre lembrada do corpo humano. Além das relações entre a escultura e a moda, na exposição, subjazem as do corpo do modelo com a escultura; e as do corpo da modelo com a moda.

Um aspecto ressaltado pela organização da mostra "Back Side/Dos à la mode" é que adotar o dorso como tema, em nossa sociedade tão obcecada pelo rosto, é apresentar algo diferente, inesperado. Sob este ponto de vista, o inesperado consiste na interação mais marcante em termos de apreensão de sentidos, conforme as teorias de Eric Landowski (2005).

Em síntese, além de tantos pontos de contato encontrados pelo curador Alexandre Samson, desde os mais óbvios como as asas de cupido e aquelas do desfile-espetáculo de Thierry Mugler, a ausência ou a despreocupação com a identidade manifesta pelos rostos, tanto nas esculturas quanto na exposição de trajes, até questões menos evidentes como a maleabilidade de materiais tão distintos, da pedra à seda, o fato é que muitas interrelações puderam ser encontradas e outras tantas foram deixadas para reflexões posteriores.

O estudo das intertextualidades presta-se não apenas para se identificarem similaridades, mas, igualmente, as diferenças. No jogo da busca de diferenças e semelhanças, aprofundam-se os modos de observação, percepção e reflexão.

O fato é que tanto o escultor quanto o costureiro modelam, moldam, talham, juntam partes, enfim, criam, constroem, arquitetam. E se fazem isto, o fazem a partir de matérias e materiais os mais diversos, mas seus resultados não podem ser tão distintos se o objeto é o mesmo, o corpo humano. Mas os modos de apresentá-lo e as proposições que sugerem são infindáveis.

E em relação às classificações e aos pressupostos teóricos sobre intertextualidade, o que dizer? ${ }^{6}$

\section{REFERÊNCIAS}

BAKHTIN, M. " Une source de l'intertextualité ? La dialogisme ". In : RABAU, Sophie. L'Intertextualité. Paris: Flammarion, 2002.

CALABRESE, O. "Lo strano caso dell'equivalenza imperfetta (modeste osservazioni sulla traduzione intersemiótica)". In: CALABRESE, $O$. Fra parola e immagine: metodologie ed esempi di analisi. Milano: Editora Mondadori Universitária de Milano, 2008. FARIAS, J. P. \& RAMALHO E OLIVEIRA, S. "O fenômeno semiótico da tradução em Omar

\footnotetext{
${ }^{6}$ Revisão gramatical e tradução: Dra. Luciane Ruschel Nascimento Garcez. Link Lattes: http://lattes.cnpq.br/8041551261651027

E-mail: lucianegarcez@gmail.com
} 
Calabrese: uma resenha". In: Revista DAPesquisa, v. 11, p. 220-234, 2012.

FIORIN, J. L. Introdução ao pensamento de Bakhtin. São Paulo: Ática, 2008.

FRANCE, A. Apologie pour le plagiat. Paris : Éditions du Sonneur, 2013.

GENETTE, G. "La transtextualité ou l'intertextualité redéfinie ". In : RABAU, S. L'Intertextualité. Paris : Flammarion, 2002.

GENETTE, G. Introduction à l'architexte. Paris : Seuil, 1979.

GREIMAS, A. J. \& J. COURTÉS. Dicionário de Semiótica. São Paulo: Cultix, 1989.

JAKOBSON, R. Lingüística e Comunicação. São Paulo: Cultrix, 1990.

JARDIM FILHO, A. J. Intertextualidade como proposta para o ensino de arte: um exercício a partir das concepções visuais de Aloisio Magalhães. 2019, 207 p. Tese (Doutorado) - Universidade do Estado de Santa Catarina, Centro de Artes, Doutorado em Artes Visuais, Florianópolis, 2019.

KOCH, I. Introdução à linguística textual. São Paulo: Martins Fontes, 2004.

KRISTEVA, J. " L'acte de naissance de l'intertextualité ou l'espace de la signification ". In RABAU, Sophie. L'Intertextualité. Paris : Flammarion, 2002.

KRISTEVA, J. Introdução à semanálise. São Paulo: Perspectiva, 1974.

LANDOWSKI, E. Passions sans nom. Paris: PUF, 2005.

LE MONDE. Alexandre Samson du Palais Galliera: " La nudité du dos est liée à l'émancipation féminine ". Entrevista a Valentin Pérez. Paris, 6 de julho de 2019.

NIEDZIELUK, L. C. "Arquitetônica bakhtiniana na leitura de retratos - um possível modus faciendi". In: Anais do X Seminário Leitura de Imagens para a Educação: múltiplas mídias. Florianópolis, 29 de novembro de 2017 - ISSN 2175-1358 7

PIĖGAY-GROS, N. Introduction à l'intertextualité. Paris : Dunod, 1996.

RAMALHO E OLIVEIRA, S. \& JARDIM FILHO, A. J. "Estudos intertextuais na visualidade: uma abordagem para o ensino da arte?" In: Anais do 26․ Encontro Nacional da ANPAP. Campinas, setembro de 2017. ISSN 2175-8212. 